\title{
COINFECÇÃO HANSENÍASE E HIV/SIDA ATENDIDOS EM UM COMPLEXO HOSPITALAR NO MUNICÍPIO DE JOÃO PESSOA/PB
}

\author{
*Stephany Pessoa Farias I \\ Bruna Braga Nóbrega de Holanda Barreto " \\ Artur Puziski Ferreira de Melo "I \\ Tafael Menezes Barros "I \\ Luciana Cavalcante Trindade ${ }^{\text {III }}$
}

\section{RESUMO}

A amplitude e o poder incapacitante da hanseníase fazem com que ela permaneça como um problema de saúde pública. A Síndrome da Imunodeficiência Adquirida (SIDA), por sua vez, mantém a sua relevância por interferir no sistema imunológico e ainda ser incurável. Devido ao potencial debilitante de ambas as doenças, e suas singularidades, este estudo objetivou avaliar os coinfectados com hanseníase e HIV/SIDA, diagnosticados de 2013 a 2017, no Complexo Hospitalar de Referência em João Pessoa/Paraíba. Trata-se de um estudo observacional, transversal, retrospectivo, descritivo. Entre os 1011 pacientes notificados com hanseníase no local e período de estudo, 15 eram coinfectados. Houve predomínio de pacientes do sexo masculino, pardos, com 20 a 59 anos de idade; apresentando as formas dimorfa e multibacilar, grau de incapacidade zero, baciloscopia negativa e ausência de reações. Hábitos de vida não saudáveis, comorbidades, infecções associadas, carga viral detectável e possível falha na adesão a terapêutica antirretroviral foram predominantes nos pacientes do sexo masculino. Concluiu-se que a coinfecção hanseníase e HIV/SIDA foi baixa no Complexo Hospitalar; porém, a relevância das singularidades dos pacientes coinfectados enseja aprimoramento das políticas públicas destinadas a essa população, notadamente a pacientes do sexo masculino.

PALAVRAS-CHAVE: Hanseníase. Infecções por HIV. SIDA

Médica, Especialista em Dermatologia. Faculdade de Medicina Nova Esperança, FAMENE CEP: 58052-130, João Pessoa, Paraíba, Brasil. *Autor correspondente: stephanyfarias@hotmail.com

ORCID ID: 0000-0002-4889-8521.

Graduada em Medicina. Faculdade de Medicina Nova Esperança, FAMENE CEP: 58052-130, João Pessoa, Paraíba, Brasil.

Orcid: 0000-0002-8352-0460; 0000-0001-5484-9008; 0000-0003-1821-064X.

Mestre. Preceptora do Serviço de Dermatologia da Faculdade de Medicina Nova Esperança - FAMENE CEP: 58052-130, João Pessoa, Paraíba, Brasil.

Orcid: 0000-0002-0643-1093. 


\section{INTRODUÇÃO}

A hanseníase é uma doença crônica, infectocontagiosa, cujo agente etiológico é o Mycobacterium leprae. A magnitude e o alto poder incapacitante mantêm a doença como um problema de saúde pública. Em 2016, 143 países reportaram 214.783 casos novos de hanseníase, o que representa uma taxa de detecção de 2,9 casos por 100 mil habitantes. No período de 2012 a 2016, foram diagnosticados 151.764 casos novos de hanseníase no Brasil, o que equivale a uma taxa média de detecção de 14,97 casos novos para cada 100 mil habitantes, refletindo uma endemicidade alta. ${ }^{1,2}$

Entre as doenças infecciosas, a hanseníase é considerada uma das principais causas de incapacidades físicas, em razão do seu potencial de causar lesões neurais. Esse alto potencial incapacitante está diretamente relacionado ao poder imunogênico do $M$. leprae. Em contrapartida, estima-se que 95\% dos indivíduos expostos ao M. leprae são naturalmente resistentes à infecção. Nos $5 \%$ susceptíveis, a doença pode manifestarse de diferentes formas, a depender de fatores relacionados ao indivíduo, tais como sexo, idade e susceptibilidade genética, ou às coletividades - como condições socioeconômicas e geográficas. ${ }^{3}$

Considerada um grande problema de saúde pública, a hanseníase tem como principais manifestações clínicas as lesões cutâneas e os danos ao sistema nervoso periférico dos pacientes. Essas manifestações sofrem a influência direta das respostas imunológicas organizadas pelo hospedeiro, relacionadas tanto a fatores genéticos, quanto a fatores ambientais. 4

A SIDA (Síndrome da Imunodeficiência Adquirida) é causada pelo vírus da imunodeficiência humana (HIV), um retrovírus pertencente à família dos lentivírus. Esse vírus de RNA, através da enzima a transcriptase reversa, possibilita a incorporação ao DNA da célula infectada, sendo o foco principal os linfócitos $\mathrm{CD}_{4+.} .5$

Os primeiros registros de casos de SIDA no Brasil ocorreram na década de 1980. No país, de 2007 até junho de 2018, foram notificados 247.795 casos de infecção pelo HIV, sendo $42.215(17,0 \%)$ na região Nordeste e, destes, 1737 (0,7\%) casos na Paraíba. O sexo mais atingido é o masculino e a faixa etária mais atingida está entre 20 e 34 anos. $^{6}$ o tratamento específico contra o vírus é a terapia antirretroviral (TARV), que surgiu na década de 80 . Atualmente, a forma mais eficiente de inibir a replicação viral é a terapia tripla, que combina três medicamentos antirretrovirais que é ofertada pelo Ministério da Saúde. ${ }^{7}$

A escassez de estudos mostrando a ocorrência de coinfecção hanseníase-HIV/ SIDA em João Pessoa configura o imperativo de maior abordagem sobre o tema. Desta maneira, esse estudo teve o objetivo de avaliar os pacientes que manifestaram coinfecção hanseníase-HIV/SIDA atendidos em um hospital de Referência na cidade de João Pessoa/PB.

\section{MATERIAL E MÉTODOS}

Trata-se de um estudo observacional, transversal, retrospectivo e descritivo, 
realizado em um Centro de Referência no atendimento e tratamento a pacientes com hanseníase, HIV/SIDA e outras doenças infectocontagiosas, localizado no município de João Pessoa/PB.

A população do estudo foi composta pelos pacientes diagnosticados com hanseníase e coinfectados com HIV/SIDA, atendidos no Centro de Referência no período de 2013 a 2017. Para a coleta de dados, inicialmente foi resgatada a relação de pacientes notificados com hanseníase no período avaliado, a partir do Núcleo de Vigilância Epidemiológica do CHCF.

O período de coleta dos dados foi em maio/2019. Foram incluídos nesta pesquisa todos os casos com diagnóstico confirmado de hanseníase e também notificados com HIV/SIDA, atendidos no ambulatório de Dermatologia Sanitária do CHCF. O critério de exclusão estabelecido foi a eliminação de alguma das infecções, no acompanhamento do paciente, caracterizando um erro diagnóstico de notificação.

O instrumento de pesquisa utilizado foi um formulário elaborado pelos autores e nele constaram como variáveis: sexo, idade, raça/ cor, comorbidades, hábitos de vida (etilismo, tabagismo e uso de drogas ilícitas), forma clínica e operacional da hanseníase, esquema de tratamento da hanseníase, reações hansênicas, contagem de $\mathrm{CD}_{4+}$, carga viral e terapia antirretroviral (TARV). Para a análise dos dados, os pacientes foram categorizados de acordo com as características de interesse.

Os dados foram apresentados em gráficos e tabelas através da planilha eletrônica do software Excel, sendo realizada a análise descritiva de todas as variáveis do estudo em termos de seus valores absolutos e relativos.

Em se tratando de uma pesquisa envolvendo seres humanos, o projeto de pesquisa analisado foi aprovado pelo Comité de Ética em Pesquisa da FACENE/FAMENE - via Plataforma Brasil, sob o CAAE: 09070519.7.0000.5179. Foram respeitadas as diretrizes e normas estabelecidas pelo Conselho Nacional de Saúde (CNS), através da resolução 466/12 CNS, assim como o anonimato e o sigilo das informações obtidas através dos documentos médicos hospitalares.

Não houve nenhum conflito de interesse na pesquisa.

\section{RESULTADOS E DISCUSSÃO}

\footnotetext{
No período de 2013 a 2017, 1011 pacientes foram diagnosticados com hanseníase no Complexo Hospitalar de Referência, em João Pessoa/PB. Destes, 15 $(1,5 \%)$ apresentaram coinfecção hanseníaseHIV/SIDA e constituíram a população do estudo. A frequência da coinfecção hanseníase-HIV/AIDS foi considerada baixa, embora um pouco mais alta do que a encontrada por outros autores 8,9 , cuja
}

frequência variou de $0,6 \%$ a 0,8\%.

No que se refere às informações sociodemográficas, $9(60,0 \%)$ pacientes eram do sexo masculino. Embora a população do estudo seja pequena, a maior frequência do HIV/SIDA no sexo masculino está de acordo com o perfil epidemiológico da doença no país e está em consonância com o percebido por outros autores. ${ }^{6,10,11}$

De 1980 até junho de 2017, foram 
registrados no Brasil 576.245 (65,3\%) casos da Síndrome em homens e 306.444 (34,7\%) em mulheres. Além disso, as taxas de detecção de SIDA em homens nos últimos dez anos têm exibido tendência de crescimento, com uma diminuição gradual dos episódios em mulheres. ${ }^{6}$

Estudos clínicos e epidemiológicos sobre hanseníase não demonstram padrão de ocorrência da doença por sexo, porém, na maioria, predomina o acometimento no sexo masculino. 2,12,13 Nos estudos sobre pacientes coinfectados com HIV/hanseníase também há um predomínio do sexo masculino.4,14

\begin{abstract}
Algumas particularidades da população masculina destacam-se para justificar, segundo autores, a maior frequência de acometimento, como a maior dificuldade em buscar os serviços de saúde, o menor interesse em cuidar da saúde e do bem-estar quando comparados as mulheres, que envolve tanto a hanseníase quanto o HIV/ SIDA. ${ }^{13,15}$
\end{abstract}

A idade dos pacientes coinfectados variou de 28 a 64 anos, com média de idade de 48,1 anos ( $D P=8,6)$. A Figura 1 mostra a frequência dos pacientes na população de estudo, conforme a faixa etária.

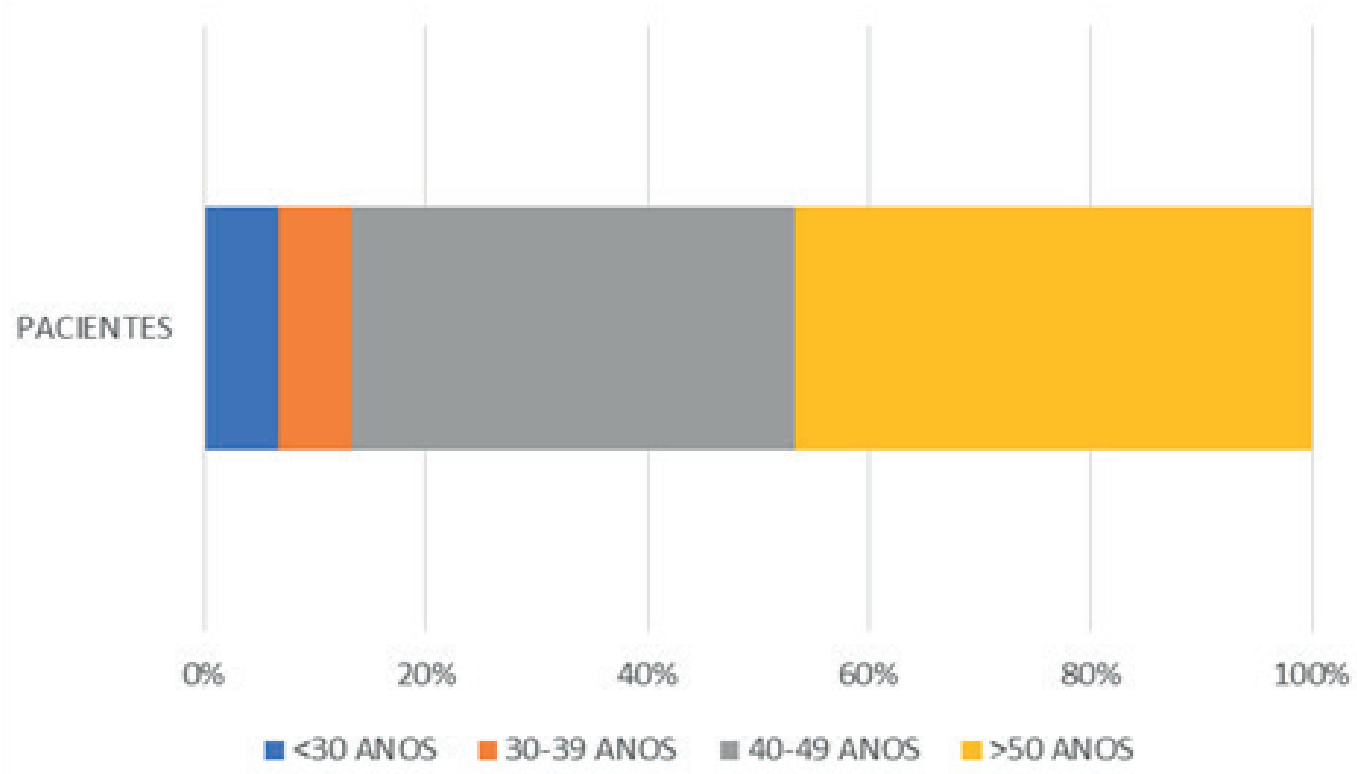

FIGURA 1: Distribuição dos pacientes com coinfecção hanseníase-HIV/SIDA atendidos no complexo hospitalar no município de João Pessoa/PB, entre 2013 e 2017, de acordo com a faixa etária.

Quando classificado O IMC por categoria, a maioria dos estudantes eram eutróficos $(68,3 \%)$. No entanto, ressaltase o percentual elevado de alunos que apresentavam sobrepeso (22,2\%), superando percentuais encontrados por Silva et al. ${ }^{6}$

Amaioria dos pacientes estava na faixa etária de 20 a 59 anos (93,3\%), enquadrando- se na população economicamente ativa, o que corrobora com a literatura vigente. ${ }^{6,13,14}$ A elevada frequência dos agravos do estudo nessa população é passível de atenção do poder público, visto que tem o potencial de sobrecarregar o sistema de saúde. Tanto a hanseníase quanto a infecção pelo HIV têm um alto potencial incapacitante e interferem 
na capacidade laboral dos acometidos, gerando impacto econômico e social, devido ao afastamento do mercado de trabalho. 4,16

Em relação a raça/cor, $8\left(5_{3,3 \%}\right)$ eram pardos, 2 (13,3\%) pretos, 2 (13,3\%) brancos e $3(20 \%)$ dos pacientes não apresentavam informações sobre essa variável no prontuário (NC). O predomínio de pardos na população estudada foi compatível com outros estudos clínicos eepidemiológicos. No caso do HIV, tem sido observado um aumento na proporção de casos entre indivíduos autodeclarados como pardos e uma queda da proporção de casos entre brancos. 6,14 Para hanseníase, no âmbito nacional, o acometimento da população parda e negra é majoritário. ${ }^{2}$

Esse predomínio pode reproduzir o contexto histórico da população negra no Brasil, que tanto representa a maior parte da população do país, quanto é a que mais padece com as desigualdades em diversos aspectos, inclusive na saúde. ${ }^{13}$ Porém, no estudo realizado em regiões onde há um predomínio da raça branca, a hanseníase também acomete mais os brancos. ${ }^{13}$ Assim, faz-se necessário considerar relevante o perfil populacional da cidade em estudo como justificativa para a relação da doença com a raça dos acometidos.

Quanto à escolaridade, 2 (13,3\%) eram analfabetos, $1(6,7 \%)$ assinava o próprio nome, $3(20 \%)$ possuíam escolaridade $<5$ anos, 5 (33,3\%) entre 5 e 9 anos, $1(6,7 \%)$ nível superior, não sendo observadas diferenças significativas, tendo em vista o tamanho da amostra. No entanto, alguns estudos epidemiológicos sobre hanseníase e HIV, com ou sem coinfecção, demonstram em geral baixa escolaridade na população acometida, sendo esta variável utilizada como um indicador da situação socioeconômica para desfechos em saúde. ${ }^{2,17,18}$

No que diz respeito a presença de comorbidades, $7(46,7 \%)$ pacientes não apresentaram nenhum tipo, 6 (40,0\%) apresentaram algum tipo de comorbidade - sendo a principal comorbidade o diabetes melitus -, e em 2 (13,3\%) essa informação não constava (Figura 2).

Ao analisar os hábitos de vida, a informação não constava em $9(60,0 \%)$ dos pacientes. Dos 6 que apresentavam, $4(66,7 \%)$ referiram o etilismo - presente unicamente no sexo masculino $-1(16,7 \%)$ era ex-tabagista e ex-etilista e 1 relata $(16,7 \%)$ uso de drogas ilícitas.

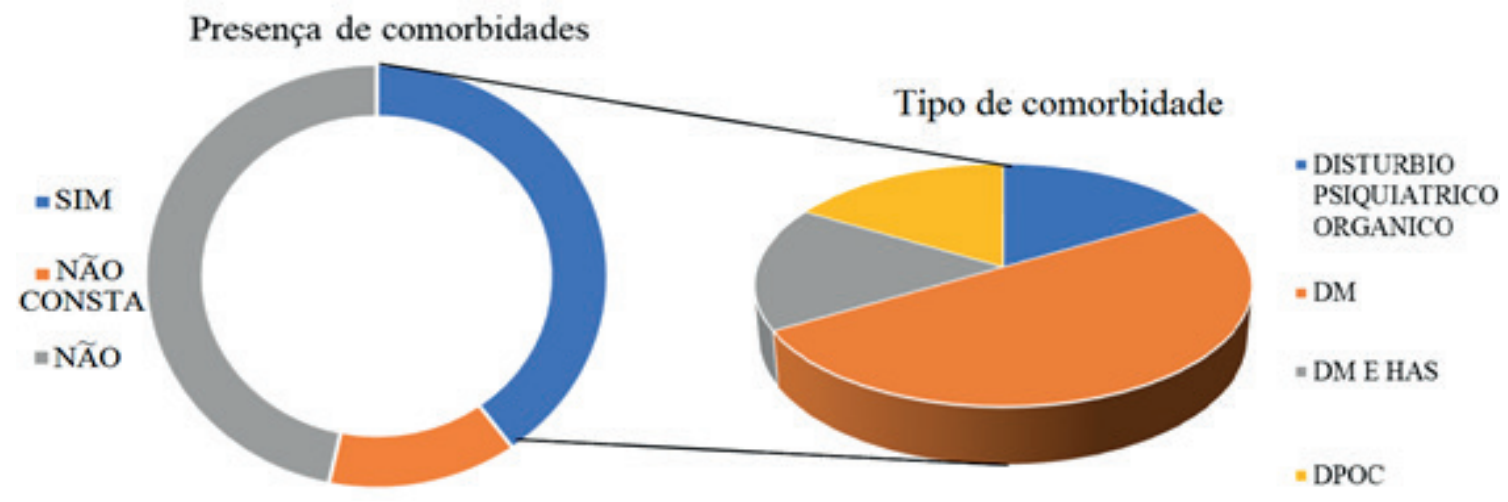

FIGURA 2: Distribuição dos pacientes com coinfecção hanseníase-HIV/SIDA atendidos no complexo hospitalar no município de João Pessoa/PB, entre 2013 e 2017, de acordo com as comorbidades associadas. DM = Diabetes melitus; HAS = Hipertensão Arterial Sistêmica; DPOC = Doença Pulmonar Obstrutiva Crônica 
A frequência de etilismo maior entre os homens é um dado compatível com outros autores, que mostraram que $17,1 \%$ dos homens são dependentes do álcool, contra $5,7 \%$ das mulheres, no âmbito nacional. ${ }^{19,20,21}$ Sobre a forma clínica, a dimorfa foi a mais notificada, seguida da tuberculoide e virchowiana, sendo o sexo masculino mais acometido pela forma dimorfa e o feminino pela tuberculoide. Quanto à forma operacional, a multibacilar foi a mais frequente, sendo o sexo masculino mais acometido pela forma multibacilar e o feminino pela paucibacilar (Tabela 1 ).

A forma clínica mais frequente na

TABELA 1: Frequência das formas clínicas e operacionais relacionadas ao sexo nos casos de coinfecção hanseníase-HIV/SIDA atendidos no complexo hospitalar no município de João Pessoa/PB, entre 2013 e 2017.

\begin{tabular}{|c|c|c|c|c|c|c|}
\hline \multirow{3}{*}{$\begin{array}{l}\text { FORMAS DA } \\
\text { HANSENIIASE }\end{array}$} & \multicolumn{4}{|c|}{ SEXO } & \multirow{2}{*}{\multicolumn{2}{|c|}{$\begin{array}{l}\text { TOTAL } \\
\text { GERAL }\end{array}$}} \\
\hline & \multicolumn{2}{|c|}{$\mathbf{F}$} & \multicolumn{2}{|c|}{$M$} & & \\
\hline & CASOS & $\%$ & CASOS & $\%$ & CASOS & $\%$ \\
\hline \multicolumn{7}{|l|}{ Forma clínica } \\
\hline Dimorfa & 1 & 16,7 & 5 & 83,3 & 6 & 40,0 \\
\hline Tuberculoide & 3 & 60,0 & 2 & 40,0 & 5 & 33,3 \\
\hline Virchowiana & 2 & 50,0 & 2 & 50,0 & 4 & 26,7 \\
\hline Total & 6 & 40,0 & 9 & 60,0 & 15 & 100,0 \\
\hline \multicolumn{7}{|c|}{ Forma operacional } \\
\hline Multibacilar & 3 & 30,0 & 7 & 70,0 & 10 & 66,7 \\
\hline Paucibacilar & 3 & 60,0 & 2 & 40,0 & 5 & 33,3 \\
\hline Total & 6 & 40,0 & 9 & 60,0 & 15 & 100,0 \\
\hline
\end{tabular}

população estudada - dimorfa seguida pela tuberculoide -, também foi observada nos estudos de Oliveira $^{1}$ e Albulquerque. ${ }^{14}$ Quanto à forma operacional, o predomínio da forma multibacilar corroborou com o achado de outros estudos $22,23,24$ e o maior acometimento dos homens pela forma multibacilar e das mulheres pela paucibacilar está em consonância com dados nacionais. 2 Sobre a poliquimioterapia ( $\mathrm{PQT}$ ) instituída, 9 (60,0\%) casos receberam a padrão multibacilar, $5(33,3 \%)$ a padrão paucibacilar, $1(13,3 \%)$ a modificada.

Em relação ao grau de incapacidade ao diagnóstico, 8(53,3\%) pacientes apresentaram grau zero, $5(33,3 \%)$ grau um, $1(6,7 \%)$ grau dois e $1(6,7 \%)$ não foi examinado (Tabela 2). O achado de grau zero de incapacidade ao diagnóstico apresentado pela maioria dos pacientes estudo foi concordante com outros autores. ${ }^{14,15}$ Ressalta-se que as incapacidades físicas decorrentes do diagnóstico tardio da hanseníase podem potencializar as limitações nas atividades cotidianas de pessoas coinfectadas pelo vírus HIV. ${ }^{14}$

Quanto a evolução do grau de incapacidade, $5(33,3 \%)$ pacientes se mantiveram estáveis, 2 (13,3\%) apresentaram melhora, 2 (13,3\%) apresentaram piora e 6 (40\%) pacientes não constavam essa informação no prontuário. Além disso, todos

TABELA 2: Evolução do grau de incapacidade nos casos de coinfecção hanseníase-HIV/SIDA atendidos no complexo hospitalar no município de João Pessoa/PB, entre 2013 e 2017.

\begin{tabular}{|c|c|c|c|c|c|c|c|c|}
\hline \multirow{3}{*}{ GRAU DE INCAPACIDADE } & \multicolumn{8}{|c|}{ EVOLUÇÃO DO GRAU DE INCAPACIDADE } \\
\hline & \multicolumn{2}{|c|}{ Estável } & \multicolumn{2}{|c|}{ Melhora } & \multicolumn{2}{|c|}{ Piora } & \multicolumn{2}{|c|}{ NC } \\
\hline & CASOS & $\%$ & CASOS & $\%$ & CASOS & $\%$ & CASOS & $\%$ \\
\hline 0 & 2 & 25,0 & 0 & 0,0 & 2 & 25,0 & 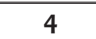 & 50,0 \\
\hline 1 & 2 & 40,0 & 2 & 40,0 & 0 & 0,0 & 1 & 20,0 \\
\hline 2 & 1 & 100,0 & 0 & 0,0 & 0 & 0,0 & 0 & 0,0 \\
\hline NC & 0 & 0,0 & 0 & 0,0 & 0 & 0,0 & 1 & 100,0 \\
\hline Total & 5 & 33,3 & 2 & 13,3 & 2 & 13,3 & 6 & 40,0 \\
\hline
\end{tabular}


os que apresentaram melhora eram do grau um, e todos que apresentaram piora pertenciam ao grau zero.

No que se refere a baciloscopia, 8 (53,3\%) casos apresentaram baciloscopia negativa, enquanto $7(46,7 \%)$ positiva. Dos que apresentaram baciloscopia positiva, o índice baciloscópico variou de 0,5\% a 3,8\%, com média de 2,5 ( $D P=1,2)$. Quanto as reações hansênicas ao diagnóstico ou durante a evolução, classificadas em neurite, eritema nodoso e reversa, 8 (53,3\%) pacientes não apresentaram nenhuma, 2 (13,3\%) apresentaram eritema nodoso, 2 (13,3\%) neurite, $2(13,3 \%)$ reversa, $1(6,7 \%)$ eritema nodoso e neurite (Figura 3 ).

Ao relacionar o aparecimento das reações hansênicas e a bacilos-copia, observou-se que dos 7 casos com baciloscopia positiva, $5(71,4 \%)$ apresentaram algum tipo de reação hansênica. Todos os casos que apresentaram reação hansênica pertenciam a forma multibacilar.

No tocante a terapêutica das reações, a prednisona foi utilizada para neurite e reversa e a talidomida para eritema nodoso. No que diz respeito ao momento em que os pacientes apresentaram as reações, todos manifestaram após concluir o tratamento da hanseníase. Além disso, $6(85,7 \%)$ pacientes que manifestaram reações, apresentaram resposta clínica favorável após a terapêutica e para $1(14,3 \%)$ não constava a informação.

As reações hansênicas (ou episódios reacionais) são processos inflamatórios agudos ou subagudos que ocorrem antes, depois ou no decorrer do tratamento da hanseníase, e guardam relação direta com a resposta imunológica do indivíduo. ${ }^{25}$

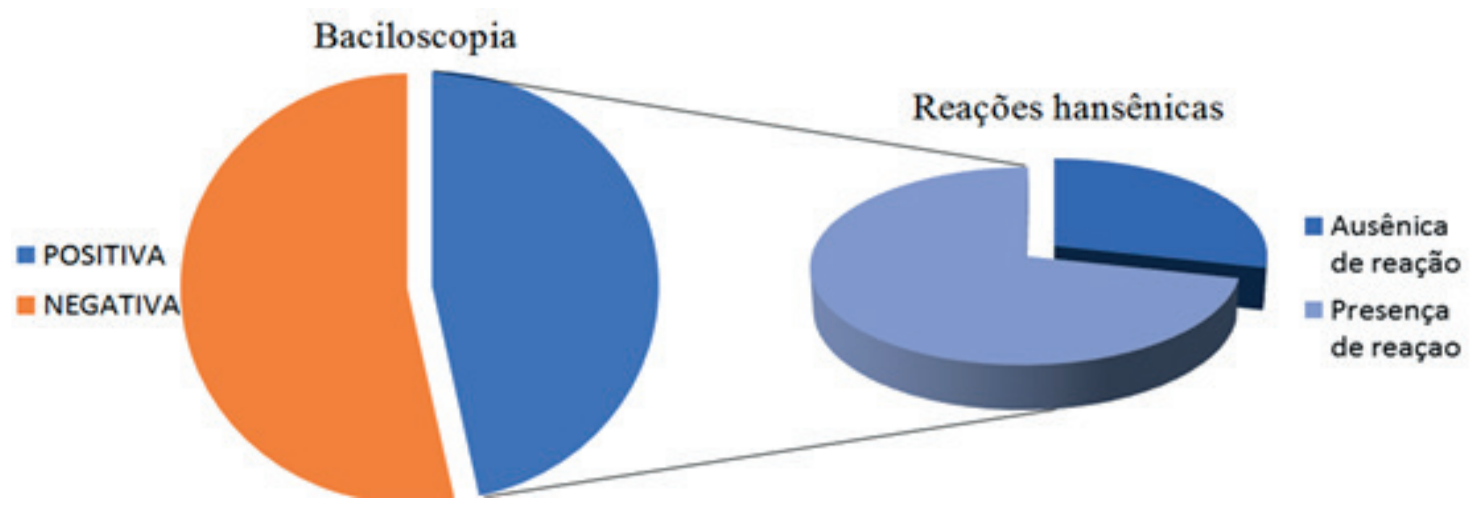

FIGURA 3: Relação entre baciloscopia e reações hansênicas nos pacientes com coinfecção hanseníase-HIV/ SIDA atendidos no complexo hospitalar no município de João Pessoa/PB, entre 2013 e 2017.

No presente estudo, quase metade dos pacientes apresentou algum tipo de reação, frequência concordante com o que foi observado por outros autores. 4,14 Pires e colaboradores, 4 estudando uma coorte de pacientes com hanseníase e HIV encontrou que as reações ocorreram na mesma frequência que a coorte de comparação (pacientes com hanseníase sem comorbidade), e quase metade dos pacientes da primeira apresentou as reações na Síndrome Inflamatória de Reconstituição Imunológica (SIRI). Nesse estudo, não foi possível saber se as reações ocorreram na vigência de uma SIRI por não ter sido objeto da pesquisa. No entanto, a maioria dos pacientes teve diagnóstico de hanseníase 
já em TARV e apresentaram as reações após concluir a terapêutica multibacilar, o que seria um período suficiente para a instalação da SIRI, que pode ocorrer meses a anos após o início da TARV, sendo mais comum após os 3 meses iniciais. 4

No que se refere a qual das infecções foi diagnosticada primeiro, 12 (80,0\%) pacientes receberam o diagnóstico de HIV/ SIDA anteriormente ao da hanseníase, 3 (20,0\%) tiveram o diagnóstico da hanseníase anterior ao do HIV/SIDA.

Ao iniciar o acompanhamento da hanseníase, $6(40,0 \%)$ pacientes apresentaram contagem de linfócitos CD4 de 350 a 500 células $/ \mathrm{mm}^{3}, 5$ (33,3\%) superior a 500 células $/ \mathrm{mm}^{3}, 1(6,7 \%)$ inferior a 350 células $/ \mathrm{mm}^{3}$ e $3(20,0 \%)$ não apresentavam a informação já que não tinham recebido diagnóstico de HIV/SIDA, sendo a média da contagem de CD4 correspondente a 608,92 células $/ \mathrm{mm}^{3}$ ( $\left.\mathrm{DP}=326,9\right)$, variando de 339 a 1324 células $/ \mathrm{mm}^{3}$. Além disso, após iniciar o acompanhamento da hanseníase, 8 (53,4\%) pacientes apresentaram carga do vírus HIV detectável, 5 (33,3\%) não detectável e para 2 $(13,3 \%)$ não constava a informação. A média da carga viral detectável foi de 11.347,38 cópias/ml ( $D P=15.107,57)$, variando de 78 a
38.347 cópias/ml.

Ao relacionar a carga viral e o sexo, observou-se que dos 8 pacientes que apresentaram carga viral detectável ao iniciar o acompanhamento da hanseníase, 6 $(75,0 \%)$ eram do sexo masculino, e dos 5 não detectáveis, $6(60,0 \%)$ eram do sexo feminino.

Em relação a outras dermatoses durante o acompanhamento, 9 (60,0\%) pacientes não apresentaram nenhuma, 5 (33,3\%) apresentaram e $1(6,7 \%)$ não continha essa informação. As dermatoses identificadas foram erisipela, escabiose, herpes zoster e infecção e necrose em $5^{\circ}$ pododáctilo direito. Ao relacionar-se a presença de dermatoses e o sexo, observou-se que $4(80,0 \%)$ pacientes eram do sexo masculino e $1(20,0 \%)$ do sexo feminino. No momento de diagnóstico da hanseníase, $12(80,0 \%)$ pacientes faziam uso da TARV, 1 (6,7\%) não fazia uso da TARV e para $2(13,3 \%)$ não constava a informação. Dos 12 pacientes que faziam uso de TARV, $8(66,7 \%)$ ainda apresentavam carga viral detectável, 3 (25,0\%) não detectável e $1(8,3 \%)$ não informava (Figura 4). Dos 8 pacientes que ainda apresentavam carga viral detectável mesmo com o uso de TARV, $6(75,0 \%)$ era do sexo masculino.

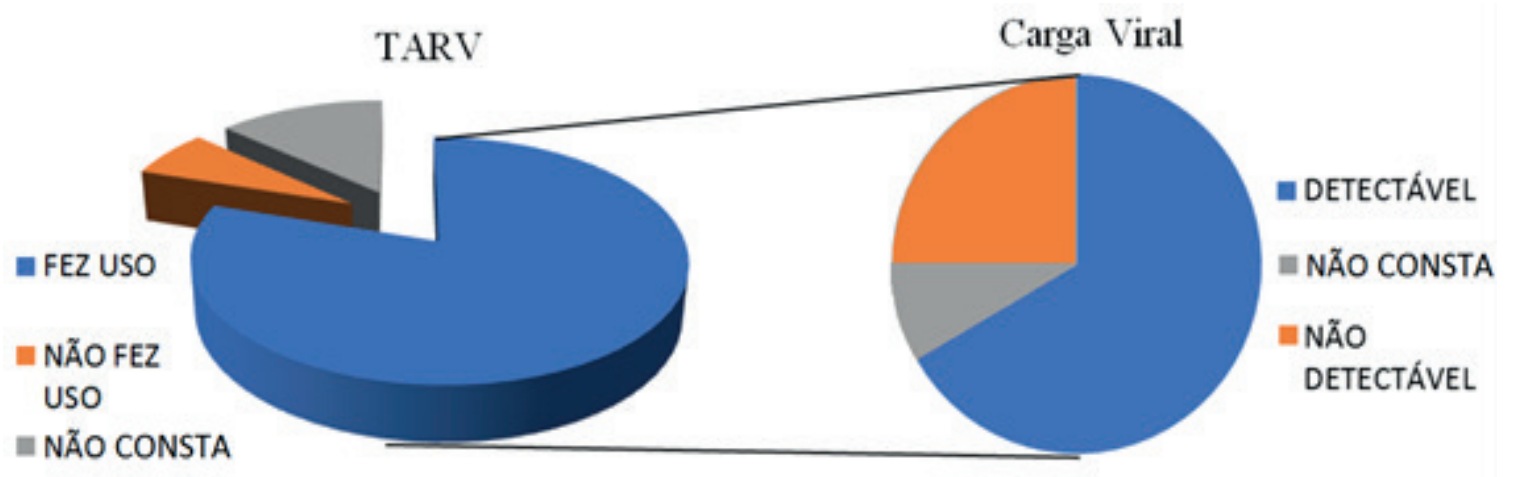

FIGURA 4: Relação entre uso de TARV e carga viral nos pacientes com coinfecção hanseníase-HIV/SIDA atendidos no complexo hospitalar no município de João Pessoa/PB, entre 2013 e 2017. 
O presente trabalho apresenta limitações relacionadas ao fato de descrever uma realidade local. Além disso, por ser um estudo retrospectivo e documental, depende de informações de prontuários, que em algumas situações apresentam informações incompletas. Adicionalmente, o tamanho reduzido da amostra impede extrapolações para outras populações.

\title{
CONCLUSÃO
}

A partir dos resultados, identificouse a predominância de pacientes do sexo masculino, em faixa etária economicamente ativa e parda com coinfecção hanseníaseHIV/SIDA. Além disso, observou-se que a presença de hábitos de vida não saudáveis, comorbidades, infecções associadas, carga viral detectável e possível falha na adesão da terapia antirretroviral foi majoritária no sexo masculino. Quanto as características clínicas relacionadas a hanseníase, a presença da forma clínica dimorfa foi superior as outras, sendo os casos multibacilares predominantes. Além disso, a maioria dos pacientes apresentou grau o (zero) de incapacidade ao diagnóstico, demonstrando evolução favorável. Em relação ao HIV, houve predomínio do uso de terapia antirretroviral, mas a grande maioria dos casos apresentou carga viral detectável.

Adicionalmente, a nítida importância de se atentar para as singularidades dos pacientes coinfectados pela hanseníaseHIV/SIDA, bem como, a necessidade que esse tema seja constantemente debatido entre profissionais de saúde e toda a população, e que políticas sejam direcionadas especialmente para esse recorte populacional. Nesse sentido, e pela deficiência de pesquisas nesta população, espera-se que os achados do presente estudo possam fomentar novas investigações, a fim de subsidiar novas políticas e o interesse de estudos subsequentes e, assim, contribuir para um melhor entendimento da coinfecção hanseníase-HIV/SIDA.

\section{COINFECTION OF HANSEN'S DISEASE AND HIV/AIDS ATTENDED IN A HOSPITAL COMPLEX IN THE MUNICIPALITY OF JOÃO PESSOA/PB}

\begin{abstract}
The breadth and crippling power of Hansen's disease make it a public health problem. Acquired Immunodeficiency Syndrome (AIDS), in turn, retains its relevance because it interferes with the immune system and is still incurable. Due to the debilitating potential of both diseases, and its singularities, this study aimed to evaluate co-infected with HIV / AIDS and Hansen's disease at a Hospital Complex located in João Pessoa / Paraíba, from 2013 to 2017. This is an observational, cross-sectional, retrospective, descriptive study. Among the 1011 Hansen's disease patients reported at the place and time of study,
\end{abstract}


15 were co-infected. There was a predominance of male, brown, 20 to 59 years old patients; with dimorphic and multibacillary forms, zero disability, negative smear and absence of reactions. Unhealthy lifestyle, comorbidities, associated infections, detectable viral load, and possible failure to adhere to antiretroviral therapy were prevalent in males. It was concluded that Hansen's disease and HIV / AIDS co infection was low in the study, similar to what was perceived by other authors; However, the relevance of the uniqueness of co-infected patients leads to the improvement of public policies aimed at this population, especially in males.

KEYWORDS: Leprosy. HIV Infections. AIDS.

\section{REFERÊNCIAS}

1. World Health Organization. Weekly epidemiological record. Geneva: World Health Organization; 2017 [acesso em 25 Jul 2019]. Disponível em: http://apps.who.int/iris/ bitstream/10665/255149/1/WER9217.pdf.

2. Brasil, Ministério da Saúde. Secretaria de Vigilância em Saúde. Departamento de Vigilância das Doenças Transmissíveis. Diretrizes para vigilância, atenção e eliminação da Hanseníase como problema de saúde pública: manual técnico-operacional [recurso eletrônico]/ Ministério da Saúde, Secretaria de Vigilância em Saúde, Departamento de Vigilância das Doenças Transmissíveis. Brasília: Ministério da Saúde; 2016.

3. Talhari S, Penna GO, Gonçalves H, Oliveira MLWDR. Hanseníase. 5. ed. São Paulo: Di Livros Editora; 2014. 217 p.

4. Pires CAA, Jucá Neto FOM, Albuquerque NC, Macedo GMM, Batista KNM, Xavier MB. Leprosy reactions in patients coinfected with HIV: clinical aspects and outcomes in two comparative cohorts in the Amazon Region, Brazil. PLoS Negl Trop Dis. 2015; 9(6): 1-14.

5. Brasil, Ministério da Saúde. Diagnóstico do HIV. Santa Catarina: Ministério da Saúde, 2014.
6. Brasil, Ministério da Saúde. Boletim Epidemiológico - HIV AIDS. Brasília: Ministério da Saúde, 2018.

7. Brasil, Ministério da Saúde. O cuidado integral da PVHIV na Unidade Básica de Saúde. Santa Catarina: Ministério da Saúde, 2017.

8. Dias RFG, Bento LO, Tavares C, Ranes Filho $\mathrm{H}$, Silva MACesário da, Moraes LC et al - Epidemiological and clinical profile of HIVinfected patients from Southwestern Goias State, Brazil. Rev. Inst. Med. trop. S. Paulo. 2018; 60: e34.

9. Vinay K, Smita J, Nikhil G, Neeta G. Human immunodeficiency virus and leprosy coinfection in Pune, India. J. Clin. Microbiol. 2009; 47(9), 2998-99.

10. Ortiz LGP, Cortés SP, Pedrero MP. Manifestaciones dermatológicas en los pacientes con VIH y su correlación conla cantidad de linfocitos CD4 en la Clínica de Infecciones de Trasmisión Sexual del Centro Dermatológico Dr. Ladislao de la Pascua. Dermatol Rev Mex. 2014; (58): 1-6.

11. Rebellato PRO, Mendívil PCG, Melo LH, Martins LAM. Manifestações dermatológicas em pacientes infectados pelo HIV-Um estudo 
de prevalência. JBM. 2015; 103(1): 31-37.

12. Peneluppi LS, Moreira MAM,Tosta TJG, Bellato HR, Olivato GB, Ribeiro CSC. Perfil Epidemiológico da Hanseníase em uma Cidade do Sul de Minas Gerais no Período de Nove Anos: estudo retrospectivo. Rev Ciências em Saúde. 2015; 5(4).

13. Oliveira MF, Oliveira NC, Caixeta KF, Castro GG. Estudo Epidemiológico da Hanseníase em Patrocínio/MG, no período 2001 a 2014. Hansen Int. 2015; 40 (2): 24-35.

14. Albulquerque NC. Atenção em saúde aos casos de coinfecção hiv/hanseníase em uma área hiperendêmica para hanseníase na Amazônia. [Dissertação]. Belém: Universidade Federal do Pará; 2016.

15. Brito AL, Monteiro LD, Ramos Junior AN, Heukelbach J, Alencar CH. Temporal trends of leprosy in a Brazilian state capital in Northeast Brazil: epidemiology and analysis by joinpoints, 2001 to 2012. Rev Bras Epidemiol 2016; 19(1):19404.

16. Oliveira JCF, Leão AMM, Britto FVS. Análise do perfil epidemiológico da hanseníase em Maricá, Rio de Janeiro: uma contribuição da enfermagem. Rev Enferm UERJ. 2014; 22(6):81521.

17. Oliveira FBM, Moura MEB, Araújo TME, Andrade EMLR. Quality of life and associated factors in people living with HIV/AIDS. Acta Paul Enferm. 2015; 28(6): 510-16.

18. Lopes VAS, Rangel EM. [Leprosy and social vulnerability: an analysis of the socioeconomic profile of users in irregular treatment]. Saúde
Debate. 2014; 103(38): 817-29.

19. Brasil, Ministério da Saúde. Perfil da Situação de Saúde do Homem no Brasil. Brasília: Ministério da Saúde; 2017.

20. Brasil, Instituto Brasileiro de Geografia e Estatística - IBGE. Tábua completa de mortalidade para o Brasil - 2017. Brasília: Instituto Brasileiro de Geografia e Estatística; 2017.

21. Centro de informações sobre saúde e álcool - CISA. Dados Epidemiológicos sobre o Uso de Álcool no Brasil. 2018 [acesso em 29 Jul 2019]. Disponível em: http://www.cisa.org.br/artigo/11/ dados-epidemiologicos-sobre-uso-alcool-no. php.

22. Queiroz TA, Carvalho FPB, Simpson CA, Fernandes ACL, Figueirêdo DLA, Knackfuss MI. Perfil clínico e epidemiológico de pacientes em reação hansênica. Rev Gaúcha de Enferm. 2015; 36(esp):185-91.

23. Palú FH, Cetolin SF. Perfil clinico epidemiológico dos pacientes com hanseníase no extremo oeste catarinense, 2004 a 2014. Arq. Catarin Med. 2015 abr-jun; 44(2): 90-98.

24. Ribeiro GC, Lana FCL. Incapacidades físicas em hanseníase: caracterização, fatores relacionados e evolução. Cogitare Enferm. 2015 [acesso em 29 Jul 2019]; 20(3):496-503. Disponível em: http://revistas.ufpr.br/cogitare/ article/view /41246/26189.

25. Medicina ambulatorial: condutas de atenção primária baseadas em evidências / Organizadores, Bruce B. Duncan... [et al.]. - 4. ed. - Porto Alegre: Artmed, 2013. 